\title{
Simposio: Reformas del año 2005 a la Constitución de la República de Chile
}



$\varepsilon 1$ 26 de agosto de 2005 se publicó en el Diario Oficial de Chile la Ley № 20.050, entrando así en vigencia una de las reformas más debatidas y de mayor alcance de las que se han introducido a la Constitución de la República de Chile del año 1980. En 1989, luego de la derrota de la propuesta de la Junta de Gobierno en el plebiscito realizado el 5 de octubre de 1988, sobre la ratificación del nombre de Augusto Pinochet como Presidente de la República, y con anterioridad a los comicios presidenciales competitivos que debían tener lugar el 11 de diciembre de ese año, la Carta de 1980 había sido sometida a numerosas modificaciones acordadas entre el Gobierno Militar y las fuerzas políticas que formaban la coalición Concertación por la Democracia, que ha gobernado Chile desde 1990. Estas reformas fueron aprobadas por plebiscito de 30 de julio de 1989 (Ley № 18.825 publicada el 17 de agosto de 1989).

Posteriormente, se sucedieron otras reformas. Subsistía, sin embargo, en el sistema constitucional, un conjunto de disposiciones conocidas por sus críticos como "enclaves autoritarios". Todas ellas han sido abordadas en la reforma de 2005, con la excepción de las que establecen el sistema electoral binominal, el cual está entregado a una ley orgánica constitucional.

La relevancia de este proceso de reforma nos motivó a organizar este simposio con la participación de siete connotados juristas chilenos expertos en Derecho Constitucional, quienes entregaron su opinión por escrito sobre cinco preguntas planteadas por el Centro de Derechos Humanos. Junto con agradecer sinceramente a todos ellos su contribución, confiamos que este simposio contribuya a comprender mejor los alcances de la reforma constitucional reciente, en especial, en lo que toca al fortalecimiento de la democracia y de la protección de los derechos humanos.

\section{Participaron en el simposio:}

José Luis Cea: Profesor titular de Derecho Político y Derecho Constitucional de la Universidad de Chile y de la Universidad Católica de Chile, Master en Derecho y Ciencia Política y Doctor en Derecho, actualmente es presidente del Tribunal Constitucional.

Rodrigo Correa: Profesor de la Universidad Adolfo Ibáñez y de la Universidad de Chile.

Enrique Navarro: Miembro del Tribunal Constitucional de Chile, Profesor de Derecho Constitucional y Director del Departamento de Derecho Público de la Facultad de Derecho de la Universidad de Chile.

Marisol Peña: Ministra del Tribunal Constitucional de Chile, Profesora de Derecho Constitucional y de Derecho Internacional Público de la Pontificia Universidad Católica de Chile.

Pablo Ruiz-Tagle: Profesor de Derecho Constitucional, Doctor en Derecho de la Universidad de Yale.
Este simposio, junto con el documento a que se refiere, están disponibles en forma digital en: www.anuariocdh.uchile.cl 
Jorge Tapia: LLM Yale University Law School, Phd. C.I. Erasmus Universiteit, Rotterdam, Decano Derecho Universidad Arturo Prat.

Patricio Zapata: Profesor de Derecho Constitucional de las Universidades Andrés Bello y Pontificia Universidad Católica de Chile, Magíster en Ciencia Política, PUC, Master en Derecho, Harvard, Doctor en Derecho, $\mathrm{UCH}$. 
1. ¿Hasta qué punto las reformas constitucionales del año 2005 responden a una nueva filosofía constitucional? ¿Puede decirse que con estas reformas ha habido cambios sustanciales en los principios fundantes de la Constitución?

\section{JOSE LUIS CEA}

Pareciere que no es posible hablar de un cambio sustantivo y global de la filosofía que inspira la Constitución a partir de la reforma de 2005. Basamos nuestra apreciación en que, tras las variadas modificaciones recibidas, han quedado casi inalterados los capítulos cruciales, esto es, las Bases de la Institucionalidad y los Derechos y Deberes constitucionales junto con las garantías de los mismos, recayendo el grueso de las modificaciones en la Parte Orgánica. Hállase, por tanto, la Parte Dogmática de la Constitución casi intacta, ¿cabe hablar por lo mismo de un cambio en el ethos constitucional?

Pero si bien no podemos decir que la filosofía que inspira la Constitución ha cambiado sustantivamente, las reformas a su Parte Orgánica, es decir, aquella parte de la misma sobre la que existía escasa conciencia constitucional y no se encontraba firmemente arraigada, han buscado superar el valor de la democracia protegida tan claramente establecida en el texto originario. Véase para esos efectos, y a modo de ejemplificar lo anterior, la supresión de los senadores institucionales o designados, entre muchas otras reformas "duras".

Por su parte, y relacionado con lo anterior, podemos detectar cambios en un valor que en el texto de 1980 se encontraba bastante presente, pero que, merced de las sucesivas reformas a la Carta Fundamental, que ya llevan diecisiete, ha retrocedido para dar más espacios a otros valores. Hablamos del valor de la seguridad nacional, tan presente en el texto original de la Constitución, y que hoy se encuentra ya bastante reducido. Hacemos mención a todas aquellas reformas duras o enclaves autoritarios, y especialmente a la transformación del Consejo de Seguridad Nacional, el cual tanto en su composición como en sus atribuciones ha sido modificado, y es hoy un organismo asesor del Primer Mandatario en cuestiones concernientes a dicha seguridad.

Pero también otros valores han sido engrandecidos en el texto constitucional. Es el caso de la solidaridad. Con anterioridad a la reforma de agosto de 2005, el valor de la solidaridad era reconocido en la Carta Fundamental en su antiguo artículo 104. Hoy, y tras la reforma, se ha convertido en una Base de la Institucionalidad, si bien de una forma más bien tímida, ya que el nuevo texto del artículo $3^{\circ}$ positiviza el valor desde el punto de vista del desarrollo equitativo y solidario entre las regiones, provincias y comunas del país, en un sentido bastante parecido al que ya se reconocía con anterioridad. No manifiesta por ello la necesariedad del reconocimiento del mismo como valor estructural de la sociedad civil, y de las relaciones que en aquella surgen. Es por ello que es deber de la doctrina y de la jurisprudencia desarrollar dicho concepto. 
1. ¿Hasta qué punto las reformas constitucionales del año 2005 responden a una nueva filosofía constitucional? ¿Puede decirse que con estas reformas ha habido cambios sustanciales en los principios fundantes de la Constitución?

\section{RODRIGO CORREA}

Una nueva filosofía constitucional debiera reflejarse tanto en el texto de la Constitución Política como en algunas decisiones políticas, muy especialmente en aquellas dirigidas a poner en marcha el sistema de defensa de la Constitución. El examen de la reforma muestra algunos cambios significativos en algunas instituciones, pero insuficientes para que resulte justificado hablar de una nueva filosofía constitucional. Por otra parte, las decisiones en torno al Tribunal Constitucional indican una fuerte continuidad con la Constitución vigente hasta antes de la reforma.

El principal cambio en el texto de la Constitución se encuentra en las instituciones asociadas a la democracia protegida. Destacan la eliminación de los senadores no elegidos popularmente, que el Consejo de Seguridad Nacional haya pasado a ser sólo un organismo asesor del Presidente de la República y que éste haya recuperado la potestad para llamar a retiro a los comandantes en jefe de las Fuerzas Armadas y al General Director de Carabineros. No ha desaparecido, sin embargo, la desconfianza en las mayorías parlamentarias. Esta desconfianza encuentra su principal expresión en las leyes orgánicas constitucionales. Su carácter supramayoritario asegura a la oposición parlamentaria la posibilidad de vetar muchas políticas gubernamentales. En los últimos años el Tribunal Constitucional -con la anuencia del Presidente de la República y del Congreso Nacional- ha intensificado muy significativamente esta característica de la Constitución. La última reforma constitucional respaldó esta intensificación. Esto resulta particularmente evidente en la regulación del procedimiento para la aprobación de los tratados internacionales, que ahora queda explícitamente sujeto a las exigencias de quórum diferenciado conforme a las distintas reservas de ley. Pero la reforma fue incluso más lejos, al exigir quórum de reforma constitucional para modificar algunos aspectos de la ley orgánica sobre votaciones populares y escrutinios (sistema binominal). La nueva potestad del Tribunal Constitucional para invalidar los preceptos legales declarados inaplicables, aunque sujeta a ciertos resguardos, es también reflejo de esta desconfianza en las mayorías parlamentarias.

La defensa de la Constitución se ha concentrado en el Tribunal Constitucional. Las principales decisiones en torno a este tribunal demuestran que ni el Presidente de la República ni el Congreso Nacional han visto un verdadero cambio de principios constitucionales con la última reforma. La reforma constitucional elevó de siete a diez los ministros que integran el Tribunal. La disposición decimocuarta transitoria de la Constitución Política mantuvo en sus cargos a los siete ministros antiguos, incluso a los designados por el Consejo de Seguridad Nacional. Al nombrar a los tres nuevos integrantes, el Congreso Nacional ha puesto de manifiesto que no ve dificultad alguna en confiar la defensa de la Constitución a juristas que demostraron un compromiso público con la versión original de la Constitución de 1980. 


\section{ENRIQUE NAVARRO}

Ciertamente se han producido cambios importantes en la filosofía que inspira el actual ordenamiento constitucional, sin perjuicio de que obviamente permanecen también intactos aspectos fundamentales de la Carta originaria.

Así, la eliminación de determinadas instituciones significará un evidente fortalecimiento del régimen democrático. En primer lugar, la supresión de los senadores designados y vitalicios, que permanecieron por 16 años. En segundo lugar, el Consejo de Seguridad Nacional -órgano que tendrá una integración mayoritariamente civil- y que queda limitado en sus atribuciones a un ente de carácter meramente consultivo y no resolutivo. Adicionalmente, las Fuerzas Armadas dejan de ser garantes de la institucionalidad, labor que compete ahora a todos los órganos del Estado.

Por otra parte, se aprecia un mayor equilibrio en la distribución del poder entre el Presidente de la República y el Congreso Nacional, lo que se constata, en primer lugar, en la reducción del mandato presidencial a cuatro años, sin reelección. A su vez, se fortalece la facultad fiscalizadora de la Cámara de Diputados a través de las citaciones a los Ministros de Estado y la consagración ahora a nivel constitucional de las comisiones investigadoras. Del mismo modo, el Congreso tendrá un rol menos pasivo en la tramitación de los tratados internacionales.

Desde otra perspectiva, el Poder Judicial se ha visto disminuido en su relevancia institucional, en particular el órgano que lo gobierna, desde que se le sustrae a la Corte Suprema el conocimiento de la inconstitucionalidad de las leyes. Además, se establece la incompatibilidad entre el cargo de Ministro de la Corte y miembro del Tribunal Constitucional, cosa que no sucedía en el texto de 1980 ni tampoco en la modificación de 1970. Por último, en materia de subrogación y reemplazo se vuelve al texto de 1925, que sitúa en el tercer lugar al Presidente de la Corte Suprema, luego de los Presidentes del Senado y de la Cámara de Diputados.

Cabe señalar que se mantienen, sin embargo, aspectos fundamentales del texto primitivo como -por ejemplo- los relativos a la concepción del hombre (y su catálogo esencial de derechos), del Estado (servicialidad y subsidiariedad) y en materia de orden público económico.

\section{MARISOL PEÑA}

En primer término, la reforma constitucional verificada por medio de la Ley № 20.050, publicada en el Diario Oficial de 26 de agosto de 2005, representa el conjunto de modificaciones más integrales introducidas a la Carta de 1980, después de aquella que se verificara por medio de la Ley № 18.825, publicada en el Diario Oficial de 17 de agosto de 1989.

El objetivo principal de la reforma constitucional del año 2005 fue perfeccionar la forma democrática de gobierno. Para los senadores de la Alianza por Chile, autores de una de las mociones que dio origen a esta 
1. ¿Hasta qué punto las reformas constitucionales del año 2005 responden a una nueva filosofía constitucional? ¿Puede decirse que con estas reformas ha habido cambios sustanciales en los principios fundantes de la Constitución? reforma, ella debía "preservar un valor fundamental que ha incorporado la actual Constitución a nuestro régimen democrático, como lo es el adecuado equilibrio de los poderes públicos" (Boletín 2526-07). El Gobierno estuvo de acuerdo con la necesidad de orientar la reforma hacia el tema de la organización del poder, pero enfocada, principalmente, a la superación de las divergencias que se habían mantenido respecto del sistema de democracia "protegida" consagrada por el constituyente originario. Así se desprende de la intervención del señor Ministro del Interior en la Comisión de Constitución, Legislación, Justicia y Reglamento del Senado, en noviembre de 2001.

A partir de los fundamentos reseñados y de las modificaciones concretas introducidas por la reforma, puede sostenerse que no ha cambiado la filosofía esencial que animó al constituyente de 1980. En efecto, su concepción valórica -plasmada sustancialmente en las Bases de la Institucionalidad- que parte del reconocimiento y valoración de la persona y de su dignidad intrínseca y que se materializa, entre otros aspectos, en principios tan importantes como el de servicialidad del Estado y el de subsidiariedad, han permanecido incólumes. Aún más, podría decirse que estos se han reforzado a través de aquellas modificaciones introducidas al Capítulo III de la Carta, referente a los derechos y deberes constitucionales.

Por lo tanto, aquellos valores y principios que, plasmados en el Capítulo I de la Constitución y proyectados en el Capítulo III, conforman su columna vertebral, adhiriendo a un modelo de constitucionalismo claramente "humanista", no han sido alterados, aunque sí perfeccionados. En efecto, los principios de equidad y solidaridad entre las regiones, provincias y comunas, que ya se encontraban inmersos en el Capítulo XIII de la Constitución, han sido traspasados ahora a las Bases de la Institucionalidad, por lo que han pasado a formar parte del conjunto de criterios hermenéuticos que deben presidir la aplicación de todo el resto de la Carta Fundamental y también del ordenamiento jurídico derivado.

En el mismo sentido, se han constitucionalizado los principios de probidad y publicidad en la actuación de los órganos del Estado, respondiendo a exigencias ineludibles de la democracia contemporánea.

\section{PABLO RUIZ-TAGLE}

Hay cambios en ciertos principios constitucionales, pero es difícil aceptar la idea que esos cambios responden a una nueva filosofía constitucional. Se trata más bien del desarrollo a nivel parlamentario de la transacción entre las filosofías constitucionales del iusnaturalismo católico conservador, la filosofía democrática y liberal y la social-demócrata que han inspirado desde 1989 la Constitución chilena. Tampoco me parece que los cambios propuestos sean realmente sustanciales y que afecten los principios fundamentales de la Constitución. Los cambios se refieren, por ejemplo, a la inclusión del principio de la solidaridad como principio de distribución del poder (artículo 3), la transparencia de la acción pública (artículo 8), el reducir el poder de los enclaves autoritarios, tal como el 
relativo a la designación de los comandantes en jefe de las fuerzas armadas (artículo 104), el mayor equilibrio del poder del parlamento versus el del Presidente y el aspirar a una concepción mas coherente de control constitucional. El principio de la solidaridad que ahora se incorpora en el artículo 3 no es enteramente nuevo, porque se contemplaba en el antiguo artículo 104, por eso, en verdad lo que se hace es extender su radio de acción. Algo semejante puede decirse acerca del nuevo principio de la transparencia del artículo 8, que está pendiente en el alcance de su interpretación y aplicación por parte de los órganos constitucionales. Asimismo, la reducción de los enclaves autoritarios es parcial por efecto del sistema electoral binominal y porque parte del poder que se quita a las fuerzas armadas y al Consejo de Seguridad Nacional se transfiere al Presidente del la Republica, produciendo acentuación del neopresidencialismo autoritario que ahora adquiere rango constitucional. Además, al mantener el Consejo de Seguridad Nacional y preservar la doctrina de seguridad nacional y en gran medida los artículos transitorios en la Constitución reformada, se conserva buena parte de la filosofía del "pinochetismo" constitucional. Por su parte, el intento de lograr un mayor equilibrio del Presidente con el Parlamento es parcial, porque el poder del Presidente sigue siendo excesivo. En definitiva, subsiste en gran medida la filosofía del constitucionalismo autoritario en la Constitución reformada, en el año 2005, sin perjuicio que ahora existe una oportunidad de cambiar esa forma de concebir nuestra Carta Fundamental. El cambio es posible por la nueva composición del Senado elegido enteramente por voluntad popular y por la nueva conformación del nuevo Tribunal Constitucional. Ambas instituciones pueden constituirse en la vanguardia de un movimiento constitucional pro democrático.

\section{JORGE TAPIA}

Las reformas del año 2005 sólo y simplemente completan un proceso de cosmética constitucional iniciado en 1989 destinado a darle verosimilitud a la transición desde el autoritarismo a la democracia. Pero ni ese proceso está concluido ni la transición terminada. Exponemos algunos hechos y reflexiones que lo demuestran:

El Gabinete del Presidente Ricardo Lagos, que llegó a acuerdos con la oposición en este aggiornamento teatral de 2005, no produjo cambios constitucionales que abrieran camino a la democratización del sistema, sino que aprovechó los avances hacia la democracia de hecho producidos para suprimir del Texto Fundamental los respectivos artículos. Así, la sujeción de las Fuerzas Armadas al poder civil y a la supremacía de la Constitución no fue resultado de las reformas. Estas fueron un mero reconocimiento de lo que había acontecido en la realidad política años antes, especialmente bajo la gestión de Lagos. La supresión de los senadores designados y vitalicios estaba desde ya y en los hechos aceptada, cuando el mero traspaso del tiempo inclinó los rasgos conservadores de ese mecanismo a favor del gobierno de turno. En otras palabras: las reformas de 2005 no abrieron cauce a nuevas relaciones de 
1. ¿Hasta qué punto las reformas constitucionales del año 2005 responden a una nueva filosofía constitucional? ¿Puede decirse que con estas reformas ha habido cambios sustanciales en los principios fundantes de la Constitución? poder, limitándose a reconocer las que en la práctica política ya se habían gestado. La caída "a lo Capone" del líder del régimen de la doctrina de la seguridad nacional había, por lo demás, preparado el escenario para hacer un cambio exigido por la decencia: un país en franca democratización no podía aparecer regido por una Constitución que seguían firmando el Dictador que la impuso y sus adláteres. Las reformas de 2005 son, por todo ello, un mero pero necesario ejercicio de pragmático higienismo político.

Por cierto que la higienización de la Carta Fundamental también responde a un predominio gradual de la filosofía democrática sobre la mentalidad pro totalitaria de la dictadura militar; pero en la medida que la transición no está concluida, no podemos afirmar que el actual texto refleja una "nueva filosofía". Subsisten aún principios fundacionales del sistema constitucional y del régimen político anterior que, en la medida que ponen o pueden poner en jaque el sistema democrático de gobierno y sociedad, impiden hablar de la instauración de una plena democracia. Nos referimos, por ejemplo, a la subsistencia del sistema binominal mayoritario para la elección de congresistas en la propia Constitución, esto como consecuencia de la Disposición $13^{a}$ Transitoria, que deja sujeta las modificaciones de la respectiva Ley Orgánica Constitucional "que digan relación con el número de senadores, las circunscripciones existentes y el sistema electoral vigente", al mismo quórum que la Constitución exige para las reformas constitucionales. Sin reformar la Constitución no se podrá cambiar el sistema de elección de diputados y senadores, y seguirá fuertemente distorsionada la capacidad de representatividad y legitimidad del sistema político. Peor aún, esta norma transitoria, en conjunción con otras introducidas en materia de regionalización, fortalece el centralismo del Gobierno y refuerza los poderes de las directivas centrales de los partidos políticos, empujando el país hacia una suerte de oligarquía política que tiene como súbditos al ciudadano común y a las regiones. La tendencia está también latente en una "no reforma constitucional", como fue el acuerdo entre partidos de no reconocer a las etnias indígenas en la Constitución. El reconocimiento parcial de un concepto cuasi-decimonónico de subsidiariedad, que se instala aun en el inciso tercero del artículo 1 (sobre Bases de la Institucionalidad) y se refleja en varios numerandos del artículo 19 , podría seguir produciendo inequidades no compatibles con un régimen democrático. Con mayor razón aún, pero en el campo de las libertades políticas y ciudadanas en general, seguirá amenazando como espada de Damocles la preeminencia que sigue teniendo como valor y principio constitucional una concepción ideologizada de "seguridad nacional", cuyos límites y las amenazas a la cual siguen indefinidos.

\section{PATRICIO ZAPATA}

Las reformas constitucionales aprobadas en 2005 constituyen cambios amplios y profundos al Texto Fundamental. Las reformas están articuladas en torno a un eje central: completar el reestablecimiento de las bases liberal-democráticas del régimen republicano chileno. 
Todas las modificaciones centrales (eliminación de los senadores designados, fin de la inamovilidad de los Comandantes en Jefe y rediseño radical del Consejo de Seguridad Nacional (COSENA) responden, efectivamente, a una filosofía común. Se trata, ni más ni menos, que de erradicar del Código Político los últimos vestigios de la concepción autoritaria del constituyente de 1980.

Las reformas son el resultado de un largo esfuerzo democratizador. Los fundamentos de los cambios pueden encontrarse ya en las primeras y fundadas críticas que el Grupo de Estudios Constitucionales dirigiera a la Constitución de 1980 en marzo de 1981. Las reformas aprobadas en 2005 no son muy distintas a las enmiendas propuestas al país en plena dictadura militar por el denominado Acuerdo Nacional (1986). No deja de llamar la atención, en todo caso, que hayan debido pasar casi 20 años desde dicho Acuerdo Nacional para que los defensores a ultranza de la Ilamada democracia protegida (principalmente la UDI) hayan finalmente aceptado la derogación de los enclaves autoritarios.

La existencia de esta modificación sustantiva no obsta, por supuesto, al hecho que la actual Carta Fundamental conserva sin modificación algunos de los principios básicos del texto original de 1980. Podría discutirse largamente si, en un balance final, los elementos de continuidad son más o menos fuertes que los aspectos reformados. Lo importante, en mi perspectiva, es que el resultado global de las reformas es el abandono de un paradigma político: la Ilamada "democracia protegida".

En mi opinión, el tema de continuidad o cambio puede ser enfocado también de otra manera. La verdadera continuidad histórica, me parece, es aquella que remite no a la experiencia de los años setenta en Chile, sino que, más bien, es aquella que se reconoce en la historia larga de nuestra casi bicentenaria República. Desde este punto de vista, la reforma de 2005 nos devuelve a nuestro cauce natural, poniendo fin a un experimento político autoritario que nunca echó raíces en nuestra cultura política. Ni los senadores designados ni la inamovilidad de los Comandantes en Jefe podían perdurar en el país que tuvo el primer Congreso de América del Sur y que, sacrificio de Portales mediante, institucionalizara tempranamente sus Fuerzas Armadas.

Más que hablar de una "nueva" filosofía constitucional, entonces, cabría decir que las reformas de 2005 han vuelto a instalar en la Constitución la "vieja" filosofía constitucional de nuestra República, la de 1810, 1833, 1925 y 1988: la democracia'.
1 Para un desarrollo más elaborado de estas materias véase "Génesis de una Reforma", en Reforma Constitucional, LexisNexis, 2005, pp. 751-759. 
2 A modo de ejemplo pueden citarse las trabas impuestas en razón del riguroso control de admisibilidad del recurso, la casi inexistente casación de oficio, o la negativa por parte de la Corte de conocer la inconstitucionalidad de forma. Para un análisis más profundo ver Saenger Gianoni, Fernando,

"Inaplicabilidad por inconstitucionalidad: jurisprudencia 19802003", en Revista Estudios Constitucionales, Año 1, № 1, 2003.

\section{Luego de las reformas al Tribunal Constitucional, ¿es posible hablar de un "sistema" de control de constitucionalidad de las leyes? Si así fuera, ¿cuáles serían las principales características?}

\section{JOSE LUIS CEA}

El concepto de "sistema" siempre implica dos notas: la unidad y coherencia, de modo que las piezas integrantes del mismo se adecuen en una armonía recíproca. Por tanto, un sistema de control de la constitucionalidad de la ley debería recoger dichas notas. Atendido esto, pasemos, pues, a revisar si la reforma ha creado un verdadero sistema de control de constitucionalidad de la ley, pero primero veamos rápidamente cómo eran antes las cosas.

Antes de la reforma de 2005, el control de constitucionalidad se encontraba dividido. Correspondía al Tribunal Constitucional realizar el control preventivo, ex ante, de la constitucionalidad de la ley, el cual puede ser facultativo u obligatorio. Por otra parte, a la Corte Suprema le correspondía el control correctivo, o ex post, de la misma. Pero sucesivos obstáculos impuestos por la Corte para la operatividad del recurso de inaplicabilidad ${ }^{2}$ Ilevó al constituyente a trasladar la inaplicabilidad hacia el Tribunal Constitucional, y de tal forma recuperar dicho arbitrio, carente en los últimos años de trascendencia para la defensa de los derechos de las personas. Así los controles preventivo y correctivo se unen bajo un mismo órgano, el Tribunal Constitucional, del cual puede decirse que es ahora el supremo intérprete de la Constitución.

Pero también la reforma incorporó un nuevo mecanismo de control: la inconstitucionalidad. De manera similar a cómo ella funciona en el control preventivo de constitucionalidad, se refiere a un control abstracto de esta especie de antijuridicidad que se produce cuando una norma inferior a la Constitución, en este caso la ley, es contraria a la misma. Al ser declarada, genera efectos generales, es decir, la sentencia estimativa de la inconstitucionalidad va a producir la eliminación del ordenamiento jurídico de la ley que ha resultado contraria a la Constitución.

Sin embargo, el acceso al arbitrio de la inconstitucionalidad no es directo, ya que, si bien se establece la acción pública para requerir al Tribunal la declaración de la inconstitucionalidad, primero debe haber sido declarado el precepto legal inaplicable en una gestión concreta.

También hay cambios a la inaplicabilidad; no se trata de un mero traspaso textual del antiguo artículo 80 al nuevo artículo 93 № 6, sino de modificaciones que van en la línea de ampliar la legitimación activa para que el juez ordinario pueda recurrir al Tribunal Constitucional. Pero otra parte es de la mayor importancia práctica, cual es que debe declarar un precepto como inaplicable en cuanto su aplicación sea contraria a la Constitución, de allí sus efectos relativos y su requerimiento de gestión pendiente. Todo ello no es otra cosa que reafirmar que la inaplicabilidad es un control concreto, pero control concreto de la interpretación que hace un juez ordinario de un precepto legal, de manera que aquella no 
pueda producir, en casos concretos, un efecto contrario a la Constitución. No es ya un control abstracto de la constitucionalidad de la ley, sino que de la aplicación (en un sentido amplio, considerando, además, la interpretación) de la misma. Ello puede llevar a que, si bien un precepto legal fuera declarado inaplicable para un caso concreto, éste pueda perfectamente ser declarado constitucional en el posterior control abstracto que se realiza mediante el mecanismo de la inconstitucionalidad.

Así es que el sistema denota su unidad: el control ex ante y ex post de la constitucionalidad de la ley, pero en cuanto a su modalidad correctiva es de tener claro que los mecanismos ideados por el constituyente son dos, y de dos naturalezas distintas: el control concreto, de aplicación y abstracto, de constitucionalidad.

\section{RODRIGO CORREA}

El control judicial de constitucionalidad de las leyes ha sufrido dos importantes cambios. En primer lugar, se concentró en el Tribunal Constitucional, perdiendo la Corte Suprema la potestad que se le confió en 1925 para declarar inaplicables por inconstitucionales las leyes. En segundo lugar se dio al Tribunal potestad para declarar inconstitucionales los preceptos legales declarados inaplicables. Sería prematuro afirmar o negar que la Constitución tenga un "sistema" de control de constitucionalidad. La respuesta dependerá en buena medida de lo que el Tribunal haga con las potestades que se le han confiado.

Un primer problema estará dado por la relación entre el control abstracto preventivo y el control represivo. Al existir ambos, y al corresponder a un mismo Tribunal, se presenta una situación completamente diversa a su existencia separada. A modo de ejemplo, las reservas de interpretación ("Ia disposición es constitucional en el entendido que debe interpretarse de tal manera") dejan de tener sentido. Por esta vía el Tribunal intentaba influir en la aplicación de una ley sobre la cual perdía todo control. Ahora que el Tribunal ha adquirido ese control, y de un modo particularmente intenso, esa otra forma de control pierde sentido.

La convivencia de controles preventivos abstractos y controles represivos concretos y abstractos o semiabstractos también presentará desafíos al Tribunal, entre ellos el de determinar el lugar que corresponde a los vicios de forma y de fondo. La Corte Suprema entendió que la inaplicabilidad sólo permite declarar la inconstitucionalidad de fondo. Esa comprensión era consistente con su carácter de control represivo abstracto. Hasta ahora el Tribunal Constitucional ha tenido una marcada preferencia por concentrarse en aspectos procedimentales. Si esta preferencia llegara a reflejarse en el control concreto, pondría gravemente en riesgo la estabilidad de la ley.

Salvo por la existencia de quórum diferenciados y por sus efectos, la Constitución no ha sido generosa en distinguir los dos controles represivos: inaplicabilidad e inconstitucionalidad. El propio Tribunal 
2. Luego de las reformas al Tribunal Constitucional, ¿es posible hablar de un "sistema" de control de constitucionalidad de las leyes? Si así fuera, ¿cuáles serían las principales características? deberá articular una doctrina que permita reconocer cuándo una declaración de inaplicabilidad debe ser seguida de una declaración de inconstitucionalidad.

\section{ENRIQUE NAVARRO}

Sin duda que una de las más grandes reformas que se ha introducido ha sido la relativa al Tribunal Constitucional, órgano que sufre alteraciones tanto en su integración como en lo relativo a su competencia, pudiendo declarar la inconstitucionalidad de un proyecto de ley y también de una ley ya vigente. Puede afirmarse que se transformará -utilizando los términos de Portales- en el "principal resorte de la máquina".

En efecto, como se sabe, a partir del 26 de febrero de 2006 el control constitucional de las leyes en su integridad queda entregado al Tribunal Constitucional. Pero no sólo eso, es posible incluso la declaración de inconstitucionalidad con efectos generales, desapareciendo así la norma del ordenamiento jurídico, lo que constituye una novedad en nuestra tradición constitucional. Cierto es que el quórum establecido resulta bastante elevado (4/5), lo que permite avizorar que será una facultad muy excepcional.

Otro punto que será de interés es el alcance que se le pueda dar al concepto "precepto legal". La Corte Suprema entendió, en general, por tal toda norma que tuviera dicha jerarquía, esto es, las leyes propiamente, decretos leyes, decretos con fuerza de ley e incluso los tratados internacionales. El proyecto de ley orgánica excluye la revisión de estos últimos, lo que resulta altamente discutible, dado que la Constitución no ha autorizado al legislador a efectuar semejante distinción. Es cierto que en los últimos 25 años jamás se presentaron peticiones a la Corte Suprema, salvo a mediados de los noventa en el caso de la Convención de La Haya sobre aspectos civiles del secuestro internacional de niños, pero ello no obsta a que sea una materia que deba ser resuelta por el sentenciador y no a priori por el legislador.

Adicionalmente, la petición de inconstitucionalidad también la puede formular el juez de la causa, lo que permite afirmar a algunos autores que a partir de este momento ningún tribunal podría en sus fallos desconocer la constitucionalidad de alguna ley, puesto que en tal caso debería formular requerimiento en tal sentido al Tribunal Constitucional.

\section{MARISOL PEÑA}

Si por sistema entendemos un todo armónico en que todas las partes convergen ordenadamente en función de un mismo objetivo a través de la interacción de todos sus componentes, es posible afirmar que la reforma constitucional de 2005 ha consagrado un "sistema" de control de constitucionalidad de las leyes por las siguientes razones:

1.Porque ha radicado, en un solo órgano-que es precisamente el Tribunal Constitucional- el control preventivo y posterior de la constitucionalidad de la ley asegurando la uniformidad de los criterios 
tendientes a asegurar la supremacía de la Carta Fundamental. Debe recordarse que, previo a la reforma, el control posterior lo ejercía la Corte Suprema a través del recurso de inaplicabilidad.

2.Porque ha radicado, también, en el mismo órgano el control abstracto y concreto de la constitucionalidad de la ley, es decir, el juicio general de contraste entre una norma legal y la Constitución ha venido ahora a ser complementado con la apreciación de la eventual inconstitucionalidad de una ley en su aplicación en una gestión judicial precisa de cualquiera índole.

3. El Tribunal Constitucional ha sido revestido, asimismo, de la facultad de declarar inconstitucional un precepto legal declarado previamente inaplicable contribuyendo a la certeza jurídica que supone la expulsión de dicho precepto del ordenamiento jurídico, en lugar de estar reclamando una y otra vez su inconstitucionalidad.

Desde esta perspectiva, nos parece que la reforma aprobada no sólo confirma dos de los roles tradicionales de los Tribunales Constitucionales y de la justicia constitucional en general, que son la defensa de la supremacía de la Constitución y la garantía de la plena vigencia del Estado Constitucional Democrático de Derecho sino que, además, incorpora un tercer rol, que se encontraba difuso antes de la reforma, referido a la protección de los derechos fundamentales de las personas, a la que puede proveerse más directamente a través del recurso de inaplicabilidad, aun cuando no se haya consagrado todavía un procedimiento como el amparo del derecho comparado.

\section{PABLO RUIZ-TAGLE}

No creo que pueda decirse que en Chile exista un nuevo sistema de control de constitucionalidad de las leyes. Lo que existe es un conjunto de órganos constitucionales que tienen atribuciones de control constitucional en el que dichas atribuciones no han sido concebidas de manera sistemática. Si entendemos por leyes las manifestaciones formales del derecho que expresan las normas y principios jurídicos que se sujetan al principio de supremacía constitucional, se amplía demasiado nuestro concepto. En este caso debemos incluir bajo la denominación leyes, las leyes interpretativas, las orgánicas, las de quórum calificado, los reglamentos, decretos, instrucciones, dictámenes, autos acordados y circulares, entre otras formas de expresión del derecho. En este sentido amplio las potestades de control constitucional se reparten entre la Contraloría y el Tribunal Constitucional, pero también intervienen en sus respectivas especialidades el Tribunal Electoral y la Corte Suprema, como cabeza de los tribunales ordinarios donde se radica la resolución de diversas acciones constitucionales. Por otra parte, todavía no se sabe cómo es que el Tribunal Constitucional establecerá criterios para el conocimiento de las acciones de inaplicabilidad que ahora quedan entregadas a su jurisdicción. Esta nueva distribución de competencias puede dar más coherencia al control ex ante y al control ex post de la constitucionalidad de las leyes, pero también se presta para que se use 
2. Luego de las reformas al Tribunal Constitucional, ¿es posible hablar de un "sistema" de control de constitucionalidad de las leyes? Si así fuera, ¿cuáles serían las principales características? como mecanismo para dilatar la tramitación de los procesos ordinarios, lo cual podría significar alterar todo el sistema de juicios. Por eso, supongo que en el ejercicio de sus atribuciones los órganos de control constitucional tienen la obligación de desarrollar una concepción más sistemática del control de constitucionalidad de las leyes que la que hemos tenido hasta ahora en Chile. Esa obligación se les debe a todos los ciudadanos chilenos que, a través de la expresión de un orden sistemático y simplificado de las acciones y los sistemas de control constitucional, deben poder comprender el derecho y la lógica del control, al menos en sus aspectos principales. El funcionamiento de un sistema de control constitucional bien ordenado es una garantía muy importante para que todos los ciudadanos puedan resguardar adecuadamente sus derechos fundamentales.

\section{JORGE TAPIA}

Aunque las reformas de 2005 han intensificado el grado de concentración de la jurisdicción y competencias sobre constitucionalidad en el Tribunal Constitucional, no puede concluirse que el país haya adoptado el sistema concentrado y monopólico en lugar del sistema difuso que ha existido a partir de 1970. En consecuencia, la respuesta a esta pregunta es "no", tanto en el sentido de falta de organicidad y consistencia del régimen creado cuanto en la coexistencia de formas de control constitucional en manos de diversos tribunales.

Si concordamos en que la tarea esencial y definitoria de un Tribunal Constitucional es garantizar que la ley y cuerpos normativos de similar jerarquía no trasgredan la Carta Fundamental, cabe admitir que recargar a este Tribunal con varias competencias que no tienen que ver con esta materia es "a-sistemático". La inorganicidad y falta de lógica y consistencia internas dan un carácter caleidoscópico y no especializado, ciento por ciento, a sus funciones, lo que puede obligar al Tribunal, como en el caso chileno bajo el actual artículo 93, a entrar en cuestiones de mérito o políticas e invadir las competencias de otros órganos, como en general podría acontecer con las competencias asignadas en los números 10 a 15 del citado artículo.

Desde otro ángulo, es también "a-sistemático" un régimen difuso de control de constitucionalidad, como sigue aconteciendo en Chile. Las competencias que el Tribunal Calificador de Elecciones y las Cortes de Apelaciones tienen en materia de calificación de elecciones o de recursos de protección y amparo, y en el caso de estas últimas, la Corte Suprema conociendo por la vía de la apelación, significan establecer sistemas distintos, si no paralelos, de control de constitucionalidad dentro del territorio nacional. Por último, aunque la competencia de los jueces ordinarios para entrar en cuestiones de constitucionalidad en virtud del principio de inexcusabilidad ha sido restringida por el № 16 del nuevo artículo 93, es posible identificar casos en que seguirá correspondiendo al juez común, ordinario o especial, pronunciarse sobre la constitucionalidad de un cuerpo normativo singular o general. 
A modo de conclusión, afirmamos que la transferencia a y concentración en manos del Tribunal Constitucional del control preventivo y represivo de constitucionalidad de las leyes ( $N^{\text {os }} 6$ y 7 del artículo 93 de la actual Constitución) no han variado la situación preexistente, de modo que no se ha creado un sistema sino que subsiste un sistema difuso de control o, si se quiere ser más preciso y gráfico, un sistema difuso asimétrico en un marco de concentración abierto.

\section{PATRICIO ZAPATA}

Aun antes de las reformas de 2005 existía en Chile un sistema de control de constitucionalidad. Lo conformaban, por una parte, el Tribunal Constitucional en cuanto control abstracto y ex ante y, por la otra, la Corte Suprema, ejerciendo un control represivo de las leyes con efectos limitados al caso concreto.

El referido sistema había merecido muchas objeciones. Por una parte, se cuestionaba, justificadamente, la composición del Tribunal Constitucional. En segundo término, se reparaba el hecho que importantes cuerpos normativos quedaran fuera del control de constitucionalidad (por ejemplo, los Autos Acordados). Finalmente, se criticaban tanto la radicación orgánica como la operatoria del Recurso de Inaplicabilidad.

En términos generales, creo que las modificaciones introducidas son positivas. En cuanto a las nuevas competencias del Tribunal Constitucional, pienso que sólo el paso del tiempo permitirá discernir fundadamente sobre la conveniencia de haber robustecido las funciones de dicho órgano.

En todo caso, el nuevo sistema de designación de los Magistrados del Tribunal Constitucional es mucho mejor que el antiguo. Desaparecen dos discutibles peculiaridades: Ios dos Ministros designados por el Consejo de Seguridad Nacional y la existencia de tres Ministros con doble militancia (Corte Suprema-Tribunal Constitucional). Se considera ahora una participación algo más equilibrada de los tres poderes clásicos del Estado: Congreso Nacional (nomina a tres Ministros), Corte Suprema (3 magistrados) y Presidente de la República (4 Ministros). 
3 Artículo 13 y Capítulo III, de la Ley Orgánica Constitucional № 18.575. Asimismo, se encuentran presentes en las Leyes Orgánicas del Congreso Nacional y en el Código Orgánico de Tribunales.

\section{3. ¿Cuáles son los alcances del nuevo artículo 8 de la Constitución Política de la República?}

Artículo $8^{\circ}$. "El ejercicio de las funciones públicas obliga a sus titulares a dar estricto cumplimiento al principio de probidad en todas sus actuaciones.

Son públicos los actos y resoluciones de los órganos del Estado, así como sus fundamentos y los procedimientos que utilicen. Sin embargo, sólo una ley de quórum calificado podrá establecer la reserva o secreto de aquellos o de estos, cuando la publicidad afectare el debido cumplimiento de las funciones de dichos órganos, los derechos de las personas, la seguridad de la Nación o el interés nacional".

\section{JOSE LUIS CEA}

Por medio de la inclusión del artículo 8, pasan a integrar parte de la Carta Fundamental dos principios rectores: el de probidad y el de publicidad de los actos de los órganos del Estado. Son éstos, pues, dos nuevas Bases de la Institucionalidad Chilena.

Como una primera cuestión, se trata de principios ya legislados. En efecto, ellos fueron recogidos en la Ley Orgánica Constitucional de Bases de la Administración del Estado ${ }^{3}$, pero con un consiguiente ámbito de aplicación limitado, pues la ley orgánica referida rige para los órganos de la Administración para los cuales ha sido establecida. Es, por tanto, la inclusión de estas dos nuevas bases de la institucionalidad, un intento por hacerlas aplicables a todo el funcionamiento del Estado, a la "función pública", en la terminología de la Constitución, que a su vez merece la más amplia interpretación posible, vinculando no sólo a todos los órganos del Estado, sino que, además, a los particulares que coadyuvan en dicha función.

Podemos reconocer en ambas la existencia de ideas valiosas para la democracia constitucional, la que supone la transparencia en las decisiones públicas, información de estas a la ciudadanía, y en forma práctica la posibilidad también de éstos de poder objetarlas, y así velar por la corrección de los servidores públicos.

Ahora bien, el primero de dichos principios rectores es el de probidad. Entendemos por la misma el correcto accionar de los funcionarios públicos y, por tanto, el alejamiento de los mismos de la corrupción, para así cumplir estrictamente el deber de servicialidad a que están llamados, y no los intereses propios. Pero en un sentido más amplio podría entenderse por "cumplimiento estricto del principio de probidad en todas sus actuaciones" un actuar diligente por parte de los gobernantes. Esta es una pregunta que puede quedar abierta.

Por su parte, la base de publicidad no sólo se extiende a los actos y resoluciones de los órganos del Estado, sino que también a sus fundamentos y a los procedimientos que se utilicen. Lo más interesante es la reserva reforzada de quórum calificado, para que sólo esta ley, y no 
un acto administrativo ${ }^{4}$, pueda establecer la reserva o secreto tanto de los actos o resoluciones como de los procedimientos o fundamentos de que utilicen, y sólo por las causales que establece precisamente el nuevo artículo 8. Corrige así el constituyente el abuso que se había generado en la práctica de considerar la reserva o secreto como la regla y no como la excepción.

Pero aquí, nuevas preguntas: ¿Qué sucede en aquellos casos donde es el organismo público el depositario de información pero aquella es de particulares, es decir, la información privada en manos públicas? ¿También es afecta a la publicidad?

\section{RODRIGO CORREA}

El artículo octavo tiene importancia normativa en cuanto declara públicos "los actos y resoluciones de los órganos del Estado, así como sus fundamentos y los procedimientos que utilicen". Se trata de un principio sano, pero que debe estar sujeto a importantes excepciones. Es así evidente que la investigación de los delitos debe estar sujeta a reserva, lo mismo que las operaciones de inteligencia (vid. la Ley № 19.974 sobre sistema de inteligencia del Estado, que sanciona con altas penas la divulgación o aprovechamiento de inteligencia sujeta a secreto); buena parte de la información que maneja el Servicio de Impuestos Internos también debe estar sujeta a reserva.

La aplicación in actum del artículo 8 es problemática. La disposición permite excepciones, pero sólo por ley de quórum calificado. Desgraciadamente el constituyente no dispuso un régimen de transición. Cabe entonces preguntarse si la disposición cuarta transitoria resulta aplicable a la reserva de ley de quórum calificado que exige el artículo 8. Esta disposición establece: "Las leyes actualmente en vigor sobre materias que conforme a esta Constitución deben ser objeto de leyes... aprobadas con quórum calificado, cumplen estos requisitos y seguirán aplicándose en lo que no sean contrarias a la Constitución, mientras no se dicten los correspondientes cuerpos legales". Tratándose de una disposición transitoria, su aplicación directa a la reserva del artículo 8 resulta anacrónica. Por otra parte, su aplicación analógica parece estar justificada en cuanto la situación regulada por la disposición cuarta transitoria es la misma que hoy presenta el artículo 8, y porque las dificultades que presentaría la regla contraria son demasiado graves.

\section{ENRIQUE NAVARRO}

Los alcances del nuevo artículo 8 de la Constitución Política de la República son, a no dudarlo, muy vastos, al constitucionalizarse principios fundamentales que ya habían sido recogidos por la legislación y antes por la jurisprudencia administrativa.

En efecto, se consagra el principio de la transparencia y de la publicidad de las actuaciones de los diversos órganos del Estado, salvo los casos excepcionales establecidos en tal sentido por el legislador-sólo mediante ley de quórum calificado- cuando la publicidad afectare el debido
4 Como era el sistema ideado por el DS № 20/2000 Secretaría General de la Presidencia, el cual, sin embargo, no se encontraba en plena armonía con lo dispuesto en el artículo 13 de la Ley Orgánica Constitucional de Bases Generales de la Administración del Estado. 
3. ¿Cuáles son los alcances del nuevo artículo 8 de la Constitución Política de la República? cumplimiento de las funciones de los órganos, los derechos de las personas, la seguridad o el interés nacional.

Como puede apreciarse, ello va a significar una profunda modificación del régimen establecido en materia de reserva o secreto, puesto que la actual legislación contemplaba situaciones de excepcionalidad, las que podían establecerse en normas legales y aun reglamentarias.

Incluso, como consecuencia de lo anterior, se dictó una norma general en este último sentido (Decreto № 26/2001 de la Secretaría General de la Presidencia), a lo que deben agregarse las respectivas resoluciones dictadas al efecto por los jefes de servicios, todo lo cual originó fuertes objeciones tanto por la doctrina nacional como también por la propia Contraloría General de la República.

A partir de ahora y mientras no se dicte la respectiva legislación especial y de quórum calificado, la totalidad de las actuaciones de los diversos órganos del Estado deberán ser públicas, a menos que exista algún fundamento de carácter legal que permita la reserva o secreto y que pudiera estimarse vigente al tenor de las disposiciones transitorias constitucionales.

De este modo, en principio, no cabría invocar normativa alguna de inferior jerarquía, como se produjo, por ejemplo, en el Senado con motivo de la designación de un Ministro de la Corte Suprema, al citarse disposiciones establecidas sólo en el reglamento interno de la Cámara Alta.

\section{MARISOL PEÑA}

Desde luego, eleva a rango constitucional el principio de probidad administrativa que había sido previamente consagrado por la Ley Orgánica Constitucional de Bases Generales de la Administración del Estado. Este mismo cuerpo legal definió este principio como "observar una conducta funcionaria intachable y un desempeño honesto y leal de la función o cargo, con preeminencia del interés general sobre el particular" (artículo 52). Se trata de una exigencia aplicable a quienes ejercen funciones públicas aun cuando no revistan necesariamente la calidad de órganos del Estado, pues lo que se trata de cautelar es el interés general, impidiendo que este sea sacrificado en función de objetivos o aspiraciones de carácter particular.

Por su parte, el nuevo artículo 8 consagra el principio de publicidad de los actos y resoluciones de los órganos del Estado así como de sus fundamentos y de los procedimientos que se utilicen, con la sola excepción de aquellas situaciones contempladas en una ley de quórum calificado, en atención a los criterios que la misma Constitución señala.

La regla general de la publicidad de las actuaciones de los órganos del Estado y de la trasparencia de sus procedimientos -recogida previamente en la Ley Orgánica Constitucional de Bases Generales de la Administración del Estado- nos parece un principio capital de la democracia contemporánea. 
La Comisión Interamericana de Derechos Humanos ha considerado, precisamente, que al tenor del artículo 13 del Pacto de San José de Costa Rica, del que Chile es parte, debe asegurarse a las personas el derecho a recibir la información proveniente de los órganos públicos, derecho que no se encontraba suficientemente amparado por el artículo 19 № 12 de nuestra Carta Fundamental, referido a las libertades de opinión y de información.

Lo anterior justifica, sin lugar a dudas, que la publicidad sea la regla general y que la reserva y el secreto queden reducidos a situaciones verdaderamente excepcionales que sólo al legislador de quórum calificado corresponde precisar.

Por otra parte, la única posibilidad de que los ciudadanos, entendidos como co-agentes y co-responsables del destino de la cosa pública, puedan ejercer sus roles es a través de la adecuada transparencia de las actuaciones de los órganos del Estado. Sólo en la medida en que estas se publiciten debidamente se podrá ejercer el necesario accountability o proceso de rendición de cuentas indispensable para la legitimidad del proceso de toma de decisiones en nuestras modernas democracias y para la superación de aquel concepto de ciudadanía que reducía la participación del ciudadano a su intervención esporádica en los procesos electorales.

\section{PABLO RUIZ-TAGLE}

En el capítulo I referido a las bases de la institucionalidad se sustituye el artículo 8 que estaba derogado, porque expresaba la idea de democracia protegida o el concepto de debate público restringido, por un nuevo texto.

Es dudoso, a mi juicio, que sea necesario consagrar a nivel constitucional el principio de probidad. Este tipo de disposiciones nos recuerdan la idea de mérito cívico del artículo 115 de la Constitución de 1823 o el artículo 249 y siguientes referidos a la moralidad nacional y las virtudes cívicas el Código Moral de Juan Egaña que acompañó a la Constitución Moralista.

Por su parte, el nuevo artículo 8 en su regulación de la transparencia de los actos públicos afecta no sólo a los actos de la administración, sino que también a las actuaciones del Poder Judicial y el Congreso. Esta disposición dice relación con el derecho fundamental de acceso a la información y debe entenderse vinculada con el artículo 19 № 12 que establece la libertad de expresión y de información. Hay, sin embargo varias disposiciones en pugna con la actual regulación en la materia y sería conveniente estudiar si se produce la derogación orgánica de las disposiciones sobre reserva o secreto de los actos de la administración o de secreto en otras áreas vinculadas a las funciones públicas.

Otra cuestión que queda pendiente es la relación que existe entre el antiguo artículo 8 y el nuevo. La idea de sustituir el antiguo artículo 8, que establecía las bases de la democracia protegida y del debate público 
3. ¿Cuáles son los alcances del nuevo artículo 8 de la Constitución Política de la República?

5 Pfeffer, Emilio, Constitución Política de la República de Chile. Anotada y Concordada". Santiago, 2005, p. 16. restringido en Chile puede hacernos creer en el espejismo que hemos superado los problemas de exclusión política constitucional en nuestro país. Pero esto está lejos de ocurrir, porque subsiste en nuestra Carta Fundamental un potencial de exclusión en las disposiciones del artículo 19 № 15 inciso sexto, y este potencial se actualiza por efecto del sistema binominal en las elecciones parlamentarias produciendo como efecto irreversible la exclusión de los representantes de la así denominada izquierda extraparlamentaria. El antiguo artículo 8 subsiste así en forma real o potencial por otros medios. El sustituir el antiguo artículo 8 por una disposición sobre transparencia y probidad resulta una curiosa paradoja constitucional, porque hace olvidar y torna invisible la exclusión y la discriminación. En definitiva, el nuevo artículo 8 obliga a la transparencia de todas las actuaciones públicas como regla general y esa idea me parece en principio positiva. Lo que no me gusta de la reforma constitucional ya aprobada es que viene de forma paradójica a borrar por sustitución y consecuentemente a hacer poco transparente la persistencia electoral del derogado artículo 8 en el sistema electoral de subsidio a la segunda mayoría y en las disposiciones del artículo 19 № 15, como expresión de democracia protegida.

\section{JORGE TAPIA}

Si en un país se ha perdido el espíritu de servicio público y con ello aumentan la falta de probidad y la falta de transparencia de los actos y resoluciones adoptados por los titulares de funciones públicas, se justifica incorporar a la Carta Fundamental una norma como la del artículo 8. Como dice un autor: "Su ubicación, a continuación de los artículos 6ํㅡ y $7^{\circ}$, no puede ser más acertada: da continuidad y concreta los elementos y presupuestos del Estado de Derecho que en dichas normas se recepcionan ${ }^{\prime \prime}$. Por cierto, es bueno reintroducir la ética en la política y el gobierno y debería hacerse otro tanto con la gran empresa que asumió funciones antes entregadas al Estado. Pero en el caso concreto parece estarse más ante un tema o episodio coyuntural que ante una norma constitucional en sentido material: no se justifica que, en un país conocido por el alto grado de probidad y bajo nivel de corrupción, se eleve al rango de base de la institucionalidad un tema que sólo debería encontrarse en la ley y el reglamento.

Podrían darse muchos ejemplos de la forma en que la ética del empleado - de mayor o menor jerarquía- del sector privado ha pasado al sector de los empleados públicos, dado que no se les ha explicado adecuadamente que, a veces, las virtudes de innovar y emprender, o generar cambios, chocan con la moral pública y con el principio de legalidad. Insistir, por tanto, en que no deben robar y deben actuar de modo transparente, es positivo y tal vez necesario; pero no se necesitaba ventilar el tema a nivel constitucional. 


\section{PATRICIO ZAPATA}

El nuevo artículo 8 de la Carta Fundamental consagra los principios de Probidad y Publicidad.

El Principio de Probidad impone a todos los titulares de órganos públicos el deber de observar una conducta intachable y un desempeño honesto y leal de las funciones respectivas, con preeminencia del interés general sobre el particular.

El Principio de Publicidad impone a todos los órganos del Estado, Gobierno, Administración, Judicatura, Congreso, entre otros, el deber de transparentar todos sus actos, resoluciones fundamentos y procedimientos, con excepción, claro está, de aquellos casos en que una ley de quórum calificado haya establecido la reserva o secreto.

En la medida que tanto la legislación como la práctica institucional se ajusten a los imperativos de esta nueva norma constitucional, especialmente en lo que respecta a la publicidad y transparencia, se habrán dado pasos importantes en la reconstrucción del sentido profundo, y original, de la palabra República, Res Publica. 
6 Un esfuerzo de delimitación de ambas figuras, (vida privada y vida pública) con ayuda de la legislación, vid.: Cea Egaña, José Luis (ed.), II Derecho Constitucional Chileno, Pontificia Universidad Católica de Chile, Santiago, 2003.

\section{4. ¿En qué sentido y medida la reforma antedicha y la reforma al artículo $19 \mathrm{~N}^{\mathrm{o}} 4$ reafirman el garantismo constitucional?}

Artículo 19. "La Constitución asegura a todas las personas:

$4^{\circ}$. El respeto y protección a la vida privada y a la honra de la persona y su familia".

\section{JOSE LUIS CEA}

Por medio de la reforma constitucional de 2005 dos son las modificaciones hechas al artículo 19 № 4 . Mediante la primera, se deroga el delito de difamación. Con ello se pone fin a una peligrosa figura que trataba un delito objetivo, tipos de ilícitos que, sin embargo, son repudiados por la doctrina penal como por los tratados internacionales vigentes en Chile. Con la derogación del inciso segundo de la disposición constitucional también desaparece la responsabilidad civil solidaria, que afectaba a los propietarios, editores, directos y administradores de los medios de comunicación social.

Una segunda modificación tiene que ver con la supresión de la protección de la vida pública de la persona, lo cual se produjo a partir de la presión de los medios de comunicación social, y que dieron lugar a uno de los puntos del veto presidencial. Es de hacer notar la dificultad que presentaba tal figura en relación a la delimitación con el concepto de vida privada, tanto en la doctrina como en la jurisprudencia ${ }^{6}$, lo que aconsejaba su modificación. Por su parte, la norma podía dar la sensación, y de hecho así lo hacía, de ahí el reclamo de los medios de comunicación de limitar el poder de fiscalización pública sobre ellos. Debemos recordar que los medios de comunicación social son la "última línea de defensa de una democracia".

Ambas modificaciones tienen como consecuencia una ampliación del ámbito de la libertad de expresión, derecho constitucional naturalmente limitado por aquel dispuesto en el 19 № 4.

Con lo anterior podemos claramente entroncar tanto la reforma al artículo 8 como al artículo 19 № 4 hacia un mayor garantismo constitucional. Y es que, como ya lo manifestamos en la respuesta anterior, el disponer de la información por parte de los ciudadanos llevará a un mayor control social sobre los gobernantes, propendiendo a la transparencia de las decisiones públicas, y así a dar mayor satisfacción a los derechos fundamentales de los ciudadanos. A su vez, propenderá a que sea mayor el ejercicio de una responsable libertad de expresión.

\section{RODRIGO CORREA}

No existe relación entre el nuevo artículo 8 y la reforma al numeral cuarto del artículo 19, salvo en un punto. La primera disposición establece el principio de probidad y el principio de publicidad de los actos del Estado. La reforma al numeral cuarto del artículo 19 eliminó la protección constitucional de la vida pública. Aunque tratan problemas 
diversos, ambas reformas encarnan el mismo espíritu: los actos del Estado deben estar sujetos a la mirada y a la crítica, aun despiadada, de los ciudadanos. Sería reduccionista atribuir esto a "garantismo". Más que de la protección del derecho, se trata de crear condiciones que hagan posible exigir responsabilidad en el ejercicio del poder público. Esto viene de alguna manera exigido por el artículo 4 de la Constitución Política.

Pero la principal reforma al numeral cuarto del artículo 19 simplemente desconstitucionaliza un problema que nunca debió haberse tratado en la Constitución Política. Corresponde al legislador determinar el grado de protección a la privacidad frente a las pretensiones de los medios de comunicación social. Es un error pensar que la eliminación del mandato de incriminación de la difamación a través de medios de comunicación social significa que estos son ahora libres para realizar intromisiones en la vida privada o para revelar información privada, por mucho que esta pudiera interesar al público. Dicha eliminación sólo significa que el legislador está menos constreñido en la regulación de este problema.

\section{ENRIQUE NAVARRO}

El garantismo constitucional ciertamente se ve reafirmado con motivo de las recientes modificaciones al Texto Constitucional, incluyendo aquellas relativas a la eliminación del delito de difamación y a la protección de la vida pública.

Sin embargo, el punto esencial parece ser la necesidad de que existan mecanismos tutelares para hacer efectivos los derechos fundamentales. En efecto, la Constitución Política reconoce diversos derechos en su artículo 19, desde el derecho a la vida, pasando por la igualdad, la libertad y el derecho de propiedad. El artículo 20 sólo tutela los derechos individuales y no así los de contenido económico social, salvo excepciones, como el derecho a vivir en un medio ambiente libre de contaminación.

Entre los derechos de contenido social y económico que no se encuentran tutelados, cabe citar el derecho a la protección de la salud (artículo 19 $\mathrm{N}^{\circ}$ 9), el derecho a la educación (artículo $19 \mathrm{~N}^{\circ} 10$ ) y el derecho a la seguridad social (artículo $19 \mathrm{~N}^{\circ} 18$ ). Del mismo modo, el derecho individual a presentar peticiones tampoco se encuentra protegido al no existir obligación constitucional de respuesta, aunque indirectamente sí a nivel legal y de jurisprudencia contralora.

Frente a dicha situación nuestros tribunales superiores han debido recurrir a otros derechos, como es el caso de la igualdad ante la ley y -principalmente- la propiedad sobre las cosas incorporales, de modo de dar debida protección a situaciones ilegales y abusivas tanto de particulares como de la autoridad, fenómeno conocido en doctrina como "propietarización de los derechos".

Un elemento interesante es aquel relativo a la modificación que se introduce al recurso de protección vinculado a materia ambiental. Ahora 
4. ¿En qué sentido y medida la reforma antedicha y la reforma al artículo $19 \mathrm{~N}^{\circ} 4$ reafirman el garantismo constitucional? también quedan incluidas las omisiones imputables a autoridad o persona determinada siempre y cuando tengan el carácter de ilegales.

Finalmente, en materia de derechos, existe una situación que nos merece profundos reparos y es aquella relativa al derecho de reunión, que aún puede ser regulado por la vía administrativa, lo que la Carta Fundamental denomina "normas generales de policía"; situación que constituye un resabio cuasi monárquico y que se puede comprobar cada vez que se escucha hablar de solicitar una "autorización" a la autoridad, siendo que se trata en realidad de una simple comunicación o aviso.

\section{MARISOL PEÑA}

Si se analiza la reforma del año 2005, desde una perspectiva general, podrá apreciarse que su centro de gravedad no estuvo puesto en el reforzamiento de la parte dogmática de la Constitución. Probablemente, porque se ha generado cierto consenso en torno a la idea de que uno de los grandes méritos de la Constitución de 1980 fue el de haber perfeccionado el catálogo de derechos reconocidos y protegidos por la Carta de 1925 junto con fortalecer el "garantismo constitucional" incorporando el recurso de protección para amparar todos aquellos derechos distintos de la libertad personal y de la seguridad individual que no constituyan meras aspiraciones sociales.

Asimismo, es preciso reconocer que la reforma introducida, en el año 1989, al artículo 5 inciso $2^{\circ}$ de la Constitución profundizó dichos avances al incorporar como deber de los órganos del Estado el de respetar y promover los derechos esenciales que emanan de la naturaleza humana garantizados no sólo por la Constitución, sino que también por los tratados internacionales ratificados por Chile y que se encuentren vigentes.

En el caso de la reforma al artículo 19 № 4 puede observarse que se ha eliminado la protección que se brindaba a la "vida pública" de las personas, entendida como aquel ámbito de la convivencia social en que se desempeñan quienes gozan de notoriedad pública aun cuando no revistan el carácter de funcionarios públicos o autoridades.

Por su parte, se eliminó la consagración del delito de difamación que se contenía en el inciso $2^{\circ}$ de aquella norma y en cuya virtud se podía sancionar a aquellos medios de comunicación social que imputaren hechos o actos falsos, o que causaren injustificadamente daño o descrédito a una persona o a su familia.

Durante la tramitación de la reforma, la Comisión de Constitución, Legislación, Justicia y Reglamento del Senado fue de opinión que "la tipificación penal de estas conductas podría significar una seria limitación para el ejercicio de las libertades de opinión y de información..." (Informe de noviembre de 2001). Agregó que nuestros ordenamientos penal y civil contemplan suficientes mecanismos para perseguir las responsabilidades derivadas de estos hechos. 
Compartimos plenamente la opinión expresada por la Comisión, pues si bien podría estimarse que la reforma ha sacrificado el bien jurídico de la protección de la vida pública, debe recordarse que los derechos fundamentales no son absolutos y que están necesariamente limitados, en forma extrínseca, por la necesidad de privilegiar otros bienes jurídicos de mayor entidad, como ocurre en este caso con la libertad de expresión, fundamento indispensable de todo régimen democrático y de la necesaria transparencia que este exige. Al respecto, la Corte Interamericana de Derechos Humanos ha señalado, en su sentencia sobre el caso "La Ultima Tentación de Cristo" (de 5 de febrero de 2001) que "la libertad de expresión, como piedra angular de una sociedad democrática, es una condición esencial para que esta esté suficientemente informada" (párrafo $68)$.

\section{PABLO RUIZ-TAGLE}

Esta es quizá una de las reformas más sustanciales en materia de derechos fundamentales y es de vital trascendencia para la libertad de expresión, porque se elimina todo el inciso segundo que contenía la base constitucional de la difamación y porque se elimina la protección de la vida pública de las personas, que expresaba un error dogmático constitucional. Sin embargo, desgraciadamente al eliminar el inciso segundo también se excluyó la regulación constitucional de la responsabilidad de los medios, lo que no parece un avance, porque el ejercicio de la libertad de expresión debe quedar también sujeta al principio de responsabilidad. La disposición decía anteriormente:

"La infracción de este precepto, cometida a través de un medio de comunicación social, y que consistiere en la imputación de un hecho o acto falso, o que cause injustificadamente daño o descrédito a una persona o a su familia, será constitutiva de delito y tendrá la sanción que determine la ley. Con todo, el medio de comunicación social podrá excepcionarse probando ante el tribunal correspondiente la verdad de la imputación, a menos que ella constituya por sí misma el delito de injuria a particulares. Además, los propietarios, editores, directores y administradores del medio de comunicación social respectivo serán solidariamente responsables de las indemnizaciones que procedan".

Es la última parte de este precepto el que creo que habría sido positivo de preservar, esto es, que se hubiese dejado la disposición que dice: "(L)os propietarios, editores, directores y administradores del medio de comunicación social respectivo serán solidariamente responsables de las indemnizaciones que procedan". En todo caso esta cuestión de la responsabilidad está tratada en la nueva ley de prensa y es posible que sea suficiente con mantener el principio de responsabilidad de los medios a nivel legal, sin necesidad de establecer su consagración a nivel constitucional. La eliminación de la difamación es positiva y se podría decir que reafirma el "garantismo" constitucional en el sentido que ya no existe base constitucional para sancionar el ejercicio de la libertad de expresión. 
4. ¿En qué sentido y medida la reforma antedicha y la reforma al artículo $19 \mathrm{~N}^{\circ} 4$ reafirman el garantismo constitucional?

\section{JORGE TAPIA}

Entendido el garantismo, sea en su función de doctrina filosófico-política sea en la de tesis metodológica, como una expansión de la constitucionalización del derecho, una limitación de la soberanía del legislador y un reforzamiento de la inexcusabilidad del juez, las reformas aludidas pueden efectivamente ser vistas como una reafirmación del garantismo constitucional. Ambas visiones dan nueva dimensión a la función del juez y del jurista en cuanto, como se ha dicho, no se limita ya a la crítica interna del derecho y su praxis, sino que se extiende a una crítica externa de las mismas que le permite dimensionar las posibles crisis de las instituciones jurídicas y de las libertades y derechos.

Sin embargo, la reforma del № 4 del artículo 19 plantea dudas a este respecto. Si bien expande el campo de visibilidad del quehacer del funcionario y, circunstancialmente, del ciudadano común, al dejar fuera de protección los aspectos de su vida pública $-y$ eso tiene un efecto favorable en la vigencia del Estado de Derecho y de la seguridad del ciudadano-, deja expuesta la vida privada a los abusos y excesos de un sistema de medios de comunicación que va a la cabeza en materia de mercantilización de sus valores y principios fundacionales. Esto revierte el sentido del movimiento garantista y pone de manifiesto que el garantismo no proporciona el solaz que se supone mientras no pueda extenderse a las reglas y acciones de los poderes fácticos.

\section{PATRICIO ZAPATA}

El texto original de la Constitución de 1980 presentaba un garantismo más bien tibio y desigual. Si, por una parte, se reforzaba significativamente la tutela de los derechos de propiedad, de asociación y económicos en general, incorporándose, además, la acción constitucional de Protección, por la otra, se consagraban inaceptables límites al pluralismo político y se preterían los derechos sociales y económicos.

La Reforma Constitucional de 1989 tuvo el merito de efectuar un primer y trascendental reforzamiento de los derechos humanos en la Carta Fundamental. Este objeto se logró, principalmente, a través de la derogación del artículo $8^{\circ}$ original y la remisión a los tratados internacionales sobre derechos humanos (nuevo inciso segundo del artículo $\left.5^{\circ}\right)$.

Entre 1990 y 2005 se aprobaron varias reformas constitucionales que tienen el efecto de reforzar el garantismo de la Carta Fundamental (Nuevo sistema de persecución criminal, ampliación del derecho a la educación, entre otros). Las reformas de 2005 profundizan esta línea. 


\section{5. ¿Hasta qué punto las reformas constitucionales han reforzado el carácter democrático del régimen político?}

\section{JOSE LUIS CEA}

Podemos afirmar plenamente que los cambios introducidos por la reforma constitucional de 2005 van en la línea de consolidar el régimen democrático. Seguramente, la dificultad y dilación de la reforma se debe a que ella comprendió los temas difíciles o polémicos, reformas "duras" o "enclaves autoritarios" como eran denominados, y que configuraban una verdadera democracia protegida. Verdaderos escollos estos que eran precisamente característicos de la Constitución de 1980, pero que, a su vez, demostraban la ideologización de una época. Es de destacar, entonces, la nueva visión que logró unir tanto al oficialismo como a la oposición para logar la reforma, sobre todo en sus aspectos orgánicos, y que podrá, por fin, ser un motivo de unión y no más de desunión. Abre entonces esta reforma el camino para una mayor conciencia democrática, y para que la Carta Fundamental sea realmente vivida.

Decimos que la reforma consolida el régimen democrático, y eso en varios órdenes de ideas. Una primera, se depura a la Constitución de añadidos autoritarios, como lo son la eliminación de los nueve senadores designados o institucionales, pasando a ser el Senado, por completo, elegido por votación popular. Modifica el régimen de inamovilidad de que gozaban los comandos de las instituciones armadas, además de hacer a todos los órganos partícipes de la delicada misión de garantizar el orden institucional de la República. Por su parte, es de suma importancia recalcar la transformación del Consejo de Seguridad Nacional en un órgano integrado por cinco autoridades civiles y cuatro uniformados, siendo su misión, únicamente, la de asesorar al Presidente de la República, cuando éste lo solicite, en materias vinculadas con la seguridad nacional.

Pero la democratización del régimen no va sólo en la supresión de los enclaves autoritarios, sino que también en la nivelación, si bien tenue, de las potestades del Presidente de la República y del Congreso Nacional. Sirven para ejemplificar aquello la supresión de la legislatura extraordinaria, el fortalecimiento de las facultades de fiscalización política, las nuevas atribuciones en la declaración de los Estados de Excepción Constitucional y en el procedimiento de aprobación de los tratados internacionales, entre otras.

Sumamente destacables son, en esta misma línea, los numerosos y trascendentes cambios introducidos al Tribunal Constitucional. Sobre todo, aquellos referentes a la inclusión de los mecanismos de inaplicabilidad e inconstitucionalidad de la ley, como mecanismos de control ex post de la aplicación (interpretación) y constitucionalidad de la ley. Permitiendo aquello que esta alta magistratura se convierta en el Supremo Defensor de la Constitución, y con ello no sólo de la supremacía constitucional, sino que de los derechos fundamentales de la persona. 
5. ¿Hasta qué punto las reformas constitucionales han reforzado el carácter democrático del régimen político?

7 Böckenförde, Ernst, "La Democracia como Principio Constitucional", en Estudios sobre el Estado de Derecho y la Democracia, editorial Trotta, Madrid, 2000, p. 81.
A pesar de todo ello, muy sensible es que no se hayan efectuado cambios en orden a aumentar la participación ciudadana en el régimen, a través de la introducción paulatina de mecanismos de participación semidirecta, y de una efectiva regionalización del país, lo que habría conducido a propender a realizar de una mejor manera el valor de la solidaridad. Queda abierta entonces la agenda.

\section{RODRIGO CORREA}

La reforma ha reforzado la democracia al eliminar las instituciones más ostensiblemente reñidas con esta forma de gobierno, como eran la inamovilidad de los comandantes en jefe, el Consejo de Seguridad Nacional y la composición del Senado. Ha mantenido, sin embargo, una importante desconfianza en las mayorías parlamentarias, que se refleja en innumerables quórum contra mayoritarios, y en la política en general, como se ve en los mecanismos para designar jueces. La Constitución sigue mostrando una preferencia por la "democracia de los acuerdos". En este sentido parece valer para el constitucionalismo chileno lo afirmado por Böckenförde respecto de las cláusulas de intangibilidad en la Ley Federal de la República Federal de Alemania: "Son en realidad un signo de que una comunidad política ha perdido la confianza en sí misma"7.

\section{ENRIQUE NAVARRO}

Indudablemente las reformas constitucionales del año 2005 han reforzado el carácter democrático del régimen político chileno vigente.

Como se ha indicado, la supresión de instituciones cuestionadas fuertemente por los actores políticos y sociales, como los senadores no elegidos por sufragio universal, la tutela de las fuerzas armadas y su rol de garantes, constituyen un avance que ciertamente perfecciona el régimen institucional.

Lo mismo puede decirse respecto del mayor equilibrio que puede observarse en materia de poderes, en particular, en la relación entre el Presidente de la República y el Congreso Nacional.

Sin embargo, aún existe evidentemente un fuerte presidencialismo, que resulta muy patente al momento de observar las facultades en materia de iniciativa y en todo lo relativo al proceso legislativo.

Por otra parte, el sistema electoral es un aspecto también trascendental que ha sido entregado al legislador. Este punto resulta de especial interés al momento de calificar el régimen político, aunque ciertamente cada sistema electoral presenta especificidades, que pueden apreciarse particularmente en las experiencias europeas (Alemania, Inglaterra o Francia).

Un aspecto que aún estimamos pendiente es aquel vinculado a la mayor participación de los ciudadanos. Como se sabe, el plebiscito es una institución propia de la democracia semidirecta y en nuestro sistema 
sólo está reservado para el caso de que exista una divergencia en materia de reformas constitucionales entre el Presidente y el Congreso Nacional, sin perjuicio de los casos en que es posible efectuar un plebiscito comunal. Parece ser interesante un adecuado estudio de esta institución, de modo que los electores se sientan más cercanos a la toma de decisiones en otro tipo de materias.

Lo mismo puede decirse respecto de la iniciativa legislativa popular, habida consideración de que existen interesantes ejemplos en países europeos y que en nuestro caso sólo queda circunscrito a un ejercicio del derecho constitucional de petición.

Por último, la participación de independientes no afiliados a partidos políticos también parece ser interesante de fortalecer, dado que hoy existe escasa posibilidad de que candidaturas independientes puedan fructificar, tanto que de hecho en la última elección parlamentaria ello sólo se dio el caso de un senador en el extremo sur del país.

\section{MARISOL PEÑA}

Las reformas introducidas al Capítulo I de la Constitución, sobre las Bases de la Institucionalidad, refuerzan la democracia, sobre todo, al elevar a rango constitucional los principios de probidad administrativa y de publicidad en las actuaciones de los órganos del Estado. Ellos tienden a reforzar el carácter de los órganos del Estado en cuanto servidores de las personas y a permitir a cada ciudadano un ejercicio más consciente, responsable y activo de sus responsabilidades en el proceso de toma de decisiones orientado a la consecución del bien común.

También podría sostenerse que la reforma al artículo 19 № 4, que ha eliminado el delito de difamación, protege el rol de los medios de comunicación social en su fundamental tarea de mantener debidamente informada a la ciudadanía sobre el curso de los asuntos que le interesan.

Las reformas introducidas al Tribunal Constitucional, sin duda, refuerzan -como lo expresamos- el Estado Democrático Constitucional de Derecho que se funda en el respeto al principio de supremacía constitucional y, particularmente, en la adecuada tutela de los derechos asegurados por la Carta Fundamental complementados con aquellos que se encuentran garantizados en los tratados internacionales ratificados por Chile y vigentes. En lo que se refiere a la supresión de los senadores institucionales o designados, largamente anhelada por un importante sector de la ciudadanía, creemos que ello no necesariamente refuerza el carácter democrático de nuestro régimen político, pues si bien la legitimidad democrática suele basarse en la generación de las autoridades públicas por el voto popular, no resultan menos legítimas aquellas otras autoridades -como los jueces- que sin tener un origen en el pronunciamiento ciudadano ejercen la soberanía en los términos que la Constitución establece, como lo precisa el artículo 5 de la Carta Fundamental. Como la Constitución es, sin duda, el reflejo del compromiso esencial de la ciudadanía en torno a su forma concreta de organización, tal legitimidad 
5. ¿Hasta qué punto las reformas constitucionales han reforzado el carácter democrático del régimen político? no puede discutirse como sí podría ocurrir a la luz del funcionamiento concreto que pudo haber tenido la institución que comentamos a partir del año 1990.

Hay quienes piensan, por su parte, que las reformas introducidas al régimen constitucional de las Fuerzas Armadas y del Consejo de Seguridad Nacional también contribuyen a reforzar el régimen democrático al eliminar de la Constitución lo que se ha denominado el "tutelaje militar". Creemos que ello no es del todo efectivo, porque las Fuerzas Armadas chilenas nunca han discutido la subordinación que les cabe a la autoridad del Presidente de la República, lo que no impide reconocer que ciertas normas -hoy eliminadas de la Carta- generaban distorsiones que dificultaban una sana y fluida relación político-militar. Esas distorsiones han sido superadas, sin duda, con la nueva composición y funciones del Consejo de Seguridad Nacional y con la atribución del rol de garantes de la institucionalidad a todos los órganos del Estado y no en forma exclusiva a las Fuerzas Armadas y Carabineros.

\section{PABLO RUIZ-TAGLE}

Es un avance en la dirección correcta de perfeccionamiento de la democracia. Sin embargo, no es posible pensar que la transición se ha cerrado o completado y que en Chile vivimos un momento constitucional plenamente democrático. Una Constitución que todavía tiene veinte disposiciones transitorias no puede considerar como cerrado o terminado su proceso de tránsito a la democracia. Además, el poder del Presidente sigue siendo excesivo y ahora ha sido reforzado en su intervención en los regímenes de excepción constitucional que pueden significar la afectación de los derechos fundamentales de las personas. También es excesivo el poder presidencial en el control de las Fuerzas Armadas y del Consejo de Seguridad Nacional, que de haber sido concebidas como instituciones que expresaban un poder de seguridad o militar contrario al constitucionalismo, ahora refuerzan el poder neopresidencial autocrático del Jefe de Estado, del gobierno y la administración. El Consejo de Seguridad Nacional sigue siendo parte del texto constitucional y puede autodictarse sus reglamentos internos y opinar sobre cuestiones constitucionales, lo que resulta antidemocrático y contrario a los principios del constitucionalismo.

Además, en la Carta Fundamental chilena todavía se mantiene un capítulo entero dedicado a las Fuerzas Armadas, lo que resulta una curiosidad entre los texto constitucionales. Las Fuerzas Armadas son en un gobierno constitucional parte de la administración del Estado y no merecen más extensión en el trato que deben dar las disposiciones constitucionales que un par de incisos generales. Por eso, mantener el tratamiento de las Fuerzas Armadas en el capítulo XI es contrario a los principios constitucionales. En el caso de Chile bastaría con que el inciso segundo del artículo 38 de la Carta Fundamental tuviese alguna referencia a las Fuerzas Armadas y sería suficiente con dejar todo lo demás a la regulación de su ley orgánica. Además, mantener en el texto de la Constitución 
reformada en calidad de consultivo el capítulo XII relacionado con el Consejo de Seguridad Nacional parece también contrario a los principios del constitucionalismo. Las Constituciones democráticas no incluyen órganos consultivos, sino que se busca que ellos sean representativos. Para los órganos consultivos bastan los reglamentos o las leyes en el caso que sean necesarios. Algo semejante puede decirse de las referencias a la doctrina de la seguridad nacional en la Constitución, y las referencias a la seguridad del Estado o términos análogos. Estas referencias las encontramos, por ejemplo, en el artículo 19 № 11 en relación con el derecho a la educación, en el artículo 19 № 15 inciso cuarto respecto del derecho de asociación y en relación con el artículo 19 № 16 inciso cuarto y séptimo en lo relativo a la libertad de trabajo. También hay referencias a la seguridad nacional o a términos semejantes en el artículo 19 № 21 sobre libre iniciativa económica, en el artículo 19 № 24 inciso segundo sobre la función social del derecho de propiedad. Este conjunto de disposiciones que expresan la doctrina de la seguridad nacional que son contrarias al constitucionalismo se completa con los deberes generales de respetar los emblemas, el deber fundamental de preservar la seguridad nacional, los valores esenciales de la tradición chilena y la obligación de conscripción obligatoria que consagra el artículo 22 de la Constitución chilena y con las arcaicas barreras que se han establecido entre la actividad política y la gremial que se expresan en el artículo 23 de la Constitución. Ante la realidad de nuestro todavía precario desarrollo constitucional, el nuevo Senado y el Tribunal Constitucional tienen la oportunidad histórica de asumir un nuevo liderazgo pro democrático.

En resumen, la reforma constitucional del año 2005 generó un nuevo momento constitucional. Se ha elaborado un texto refundido y se ha suscrito la nueva Carta Fundamental dejando atrás las firmas de Augusto Pinochet y sus ministros. Sin embargo, el poder simbólico de dicho momento no alcanza para cerrar la transición. Es que son muchas y muy significativas las cuestiones pendientes. Por eso, el nuevo texto refundido será un primer antecedente de una nueva Constitución. El segundo consiste en asentar un nuevo liderazgo pro democrático en el Congreso y en el Tribunal Constitucional. Es que ahora más libre de ataduras autoritarias será posible desarrollar nuevas prácticas pro democráticas. Ahora sí podremos aspirar a la nueva Constitución del Bicentenario que no debe ser la Constitución de Augusto Pinochet ni tampoco la de Ricardo Lagos. Ahora sí podremos aspirar a una Constitución que nos represente a todos los chilenos.

\section{JORGE TAPIA}

La opinión al respecto ya está adelantada en la respuesta dada a la primera pregunta o cuestión planteada. Si bien es cierto que las reformas pusieron fin a varios enclaves autoritarios, no es menos cierto que ellos habían dejado de hecho de operar como tales años atrás. Es cierto que pudo darse expresión formal y literal a la supremacía del poder civil legítimo sobre las Fuerzas Armadas, y ponerse fin a la absurda intervención directa del Consejo de Seguridad Nacional en la generación de miembros de 
5. ¿Hasta qué punto las reformas constitucionales han reforzado el carácter democrático del régimen político?

8 Ver Tapia Valdés, Jorge, "Descentralización, regionalización y neosubsidiariedad", en Zúñiga Urbina, Francisco

(Coordinador), Reforma

Constitucional, Santiago, 2005, y

"Las Reformas

Constitucionales de 2005, un triunfo del centralismo" en La Constitución Reformada de 2005, Coordinador Humberto Nogueira Alcalá, Centro de Estudios Constitucionales de la Universidad de Talca, 2005. órganos claves, como el Senado y el Tribunal Constitucional. Pero los mecanismos de inclusión y participación, y, por tanto, los niveles de representatividad, y con ello de responsiveness y accountability, siguen bloqueados. El sistema no ha avanzado un paso, sino más bien retrocedido, en el expresado propósito de reemplazar el sistema binominal mayoritario por una forma modificada de representación proporcional. Las Cámaras se han negado a reconocer la multiculturalidad de la sociedad chilena y en forma espuria han una vez más negado su aprobación al Convenio 169 de la OIT y al reconocimiento de los pueblos indígenas en la Constitución algo que serviría más como principio educativo y formativo de los criollos y huincas que como garantía del reconocimiento de los derechos de dichos pueblos. Por último, el Estado pone reversa al proceso de modernización en su relación con la regionalización y descentralización, materias que por razón de espacio no puedo abordar acá y que son objeto de otros trabajos ${ }^{8}$.

\section{PATRICIO ZAPATA}

Las reformas de 2005 tuvieron el mérito de subsanar los principales y más evidentes defectos de la institucionalidad política chilena. En efecto, tanto la existencia de un Parlamento completamente elegido por la ciudadanía como la eliminación de las normas que entregaban algún margen de deliberación política a los Comandantes en Jefe de las Fuerzas Armadas son progresos innegables.

Ahora bien, lo expuesto no obsta, por supuesto, a que todavía existan otras áreas en las que caben nuevas modificaciones. Así, por ejemplo, me parece que tanto la sustitución del sistema electoral binominal por alguna formula más proporcional, como la implantación de una verdadera descentralización política, son reformas muy importantes para los efectos de darle más vitalidad a nuestra democracia. 